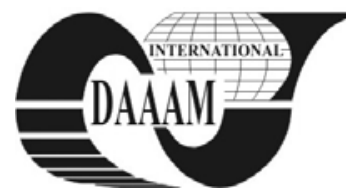

Annals of DAAAM for 2011 \& Proceedings of the 22nd International DAAAM Symposium, Volume 22, No. 1, ISSN 1726-9679 ISBN 978-3-901509-83-4, Editor B. Katalinic, Published by DAAAM International, Vienna, Austria, EU, 2011 Make Harmony between Technology and Nature, and Your Mind will Fly Free as a Bird Annals \& Proceedings of DAAAM International 2011

\title{
INTERACTION OF BIAG11 SOLDER WITH CU, AG AND NI SUBSTRATES
}

\author{
CHACHULA, M[ichal]; KOLENAK, R[oman] \& KOLENAKOVA, M[onika]
}

\begin{abstract}
The aim of this contribution is to look at the interactions between BiAg11 solder and $\mathrm{Cu}$, $\mathrm{Ag}$ and $\mathrm{Ni}$ substrates in detail. A degree of interaction was determined on the basis of wetting angles. The best wetting angle of $18^{\circ}$ was measured in the case of $\mathrm{Ag}$ substrate with the application of flux. Unsatisfactory wetting angle of $146^{\circ}$ was attained in case of Ni substrate with the application of flux. The sizes of wavy interfaces were determined by the EDX microanalysis and this experiment was aimed at finding in which cases the application of substrates resulted in the formation of intermetallic compounds and when only a eutectic reaction occurred. The intermetallic compound was created only during the application of Ni substrate. The results showed that shorter endurance and addition of flux resulted in better interaction between BiAg11 solder and $\mathrm{Cu}$ or Ag substrates. On the contrary, longer time of endurance without the application of flux caused better interaction between $\mathrm{Ni}$ substrate and the solder used.
\end{abstract}

Key words: solder, wetting, transitional area, flux

\section{INTRODUCTION}

$\mathrm{Sn}-\mathrm{Pb}$ based alloy was the most commonly used solder alloy for electronic industry. The harmful effects of lead are generally well known, and therefore, all soldering materials are being substituted for lead-free ones. However, PbSn5 and PbSn10 solders with high lead content are still utilized in the applications where higher temperature is required because no existing substitutes have been developed. Nevertheless, there are alternative solders whose qualities are similar to leadcontaining solders (Zhao at al., 2004). These include precious metals such as gold (AuSn20, AuGe12) and silver (BiAg11, SnAg25Sb10). BiAg11 solder was chosen for the experiment due to more affordable price than Au based solders and higher melting point in comparison to SnAg25Sb10 solder.

\section{EXPERIMENT}

$\mathrm{Cu}, \mathrm{Ag}$ and Ni substrates as well as the solder consisting of $89 \%$ of $\mathrm{Bi}$ and $11 \%$ of $\mathrm{Ag}$ were chosen for the experiment. Not only the melting point had to be in the range from $260{ }^{\circ} \mathrm{C}$ to $450{ }^{\circ} \mathrm{C}$ but also solder had to have satisfactory tensile strength and reasonable price. Vacuum casting was performed in order to ensure the $99.99 \%$ purity of the solder alloy (Song at al., 2006). The sizes of samples were $40 \times 40 \times 2 \mathrm{~mm}$. A production procedure of the first three samples began with putting 1 gram of BiAg11 solder to the centre of clean and degreased surface of each sample. Samples were soldered in an air furnace at the temperature of $380{ }^{\circ} \mathrm{C}$ for 30 minutes. A production procedure of other three samples was similar with the difference that in final stage to this 1 gram of BiAg11 solder we added flux. Samples were soldered in an air furnace at the temperature of $380{ }^{\circ} \mathrm{C}$ as well. The endurance at this temperature differed, however, it was only 10 seconds. The aim of the experiment was to learn about the interactions between
BiAg11 solder and $\mathrm{Cu}, \mathrm{Ag}$ and $\mathrm{Ni}$ substrates and also determine the influence of flux and its effects. The level of interaction was determined on the basis of wetting angles. Tests of wettability of BiAg11 solder were conducted with the help of goniometric method. The lower the angle; the better interaction can be expected. Flux can help the interaction but it depends also on the type of the substrate. Samples were prepared metalographically with the aim to determine the contact wetting angles and perform observations of the solder-substrate interface. Since the samples were in corroded state the results proved the presence of phases and visible wavy interfaces. The EDX analysis was utilized to monitor the change in the concentration of elements on the determined line through the defined area of phase interface. These areas included the areas of dark phases, matrix and the areas of phase interface.

\section{RESULTS}

First, the samples with $\mathrm{Cu}$ substrates were measured. The sample without the application of flux had the wetting angle of $91^{\circ}$ which means unsatisfactory wettability (Fig. 1 a). Negative effects included the formation of visible hollows. On the contrary, in the sample with the application of flux the wetting angle was $25^{\circ}$ which means good wettability (Fig. $1 \mathrm{~d}$ ).
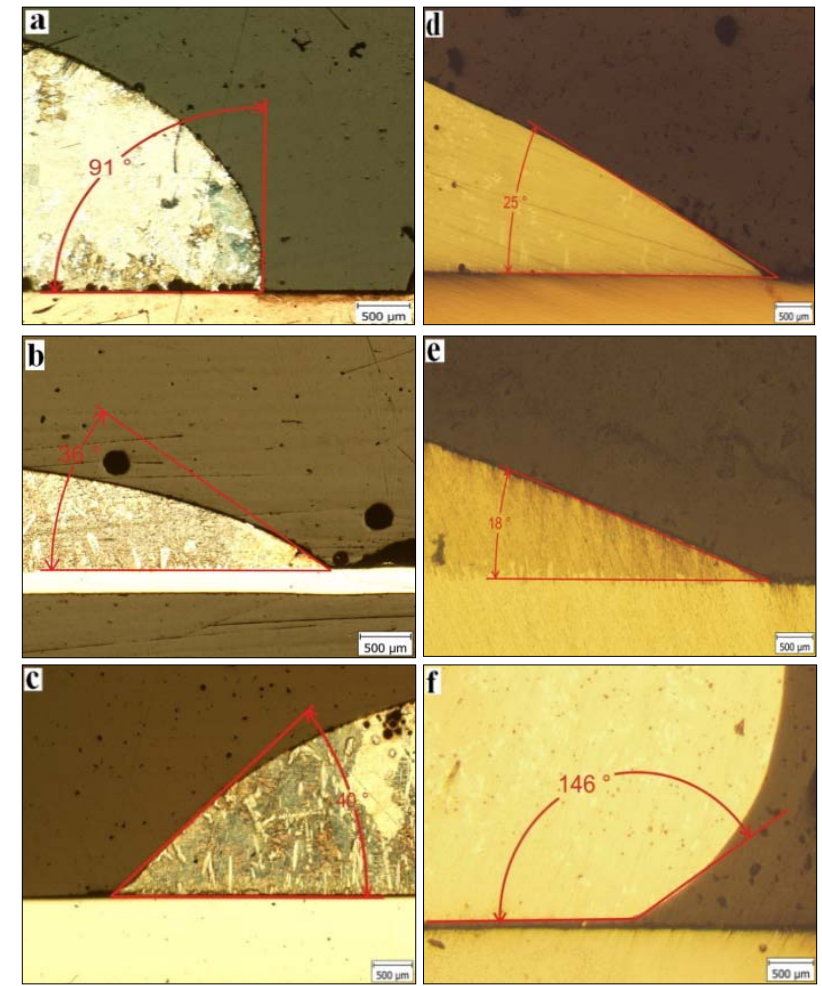

Fig. 1. Angles of wettability on $\mathrm{Cu}(\mathrm{a}), \mathrm{Ag}$ (b) and $\mathrm{Ni}$ (c) substrate without flux and $\mathrm{Cu}(\mathrm{d}), \mathrm{Ag}(\mathrm{e})$ and $\mathrm{Ni}$ (f) with flux 
Satisfactory results were recorded in both cases when samples with $\mathrm{Ag}$ substrates were utilized. The sample without the application of flux had the wetting angle of $36^{\circ}$ which means good wettability (Fig $1 \mathrm{~b}$ ) and the sample with the application of flux had very good wettability of $18^{\circ}$ (Fig. 1 e). The results of samples regarding wetting angles with Ni substrates were as follows. In case of the sample without the application of flux the angle was $40^{\circ}$ which still means good wettability (Fig. $1 \mathrm{c}$ ). Unsatisfactory value of $146^{\circ}$ was recorded in the sample with the application of flux (Fig. $1 \mathrm{f}$ ). Visible gap between BiAg11 solder and Ni substrate proves that there were unwetted areas.

The EDX analysis was performed only on those samples which recorded the best values of wetting angles (Figs. 1 c,d,e).

Based on the images from the EDX analysis it is visible that $\mathrm{Cu}$ does not dissolve either in $\mathrm{Bi}$ or Ag. Independently on the fact whether flux was applied or not, there was no intermetallic compound between $\mathrm{Bi}$ and $\mathrm{Cu}$ elements, and only a eutectic reaction occurred with expected weak interaction between solder and the $\mathrm{Cu}$ surface at the temperature of $270^{\circ} \mathrm{C}$. The size of wavy interface reached $1 \mu \mathrm{m}$ and was insignificant (fig. 2). Eutectic reaction was not significant as well.

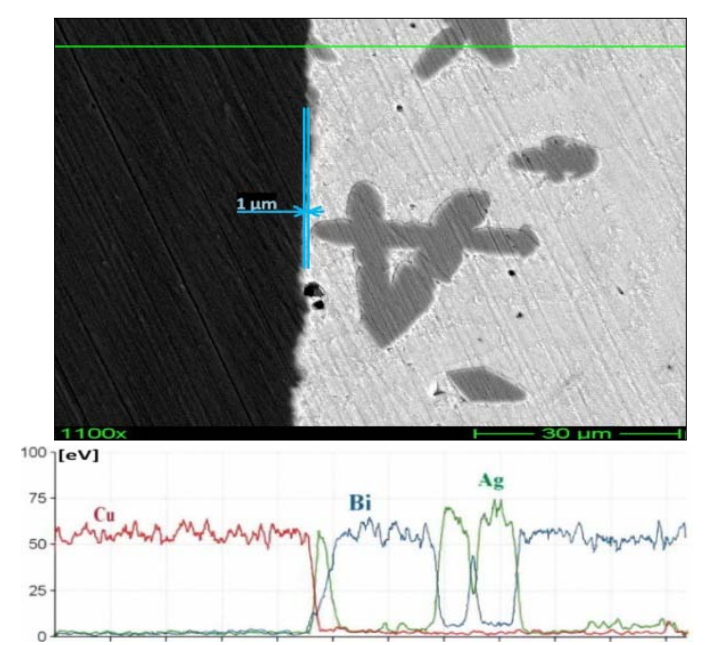

Fig. 2. EDX analysis of BiAg11 solder- Cu substrate fabricated with the use of flux and line profiles of elements present.

During soldering Ag substrates with BiAg11 solder, a eutectic reaction with more significant interaction between solder and surface occured. There was higher probability that primary material would be wetted. The more significant eutectic reaction occurs, the bigger is the waving effect. The size of wavy interface of $3.5 \mu \mathrm{m}$ is depicted on the fig. 3.

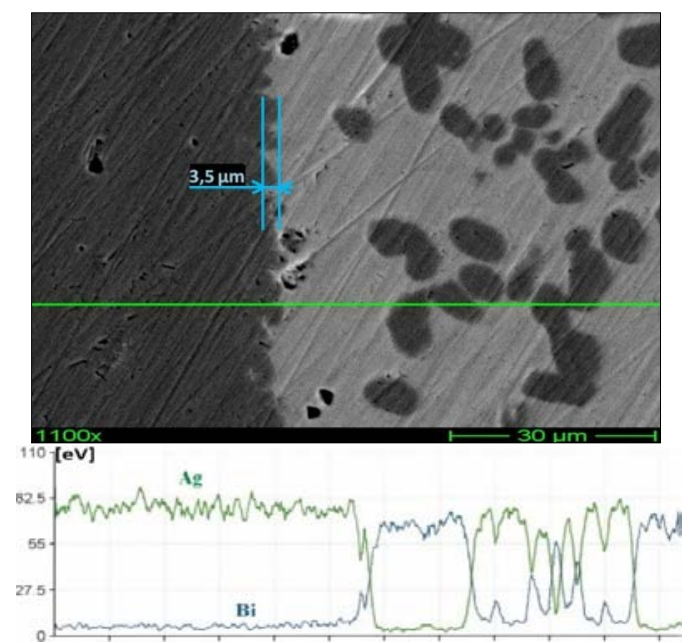

Fig. 3. EDX analysis of BiAg11 solder- Ag substrate fabricated with the use of flux and line profiles of elements present
The complexity of this process was determined by low solubility of Ag in Bi in the liquid state (Liang, 2007).

During the interaction of BiAg11 solder with Ni substrate, the formation of inter-layer of chemical compound was expected. According to Ni-Bi binary diagram, the formation of $\mathrm{NiBi}_{3}$ intermetallic compound was the most probable at the temperature of $271^{\circ} \mathrm{C}$. Then $\mathrm{Ni}$ dissolved to $\mathrm{NiBi}_{3}$. The width of formed $\mathrm{NiBi}_{3}$ intermetallic compound was $20 \mu \mathrm{m}$ (Fig. 4).

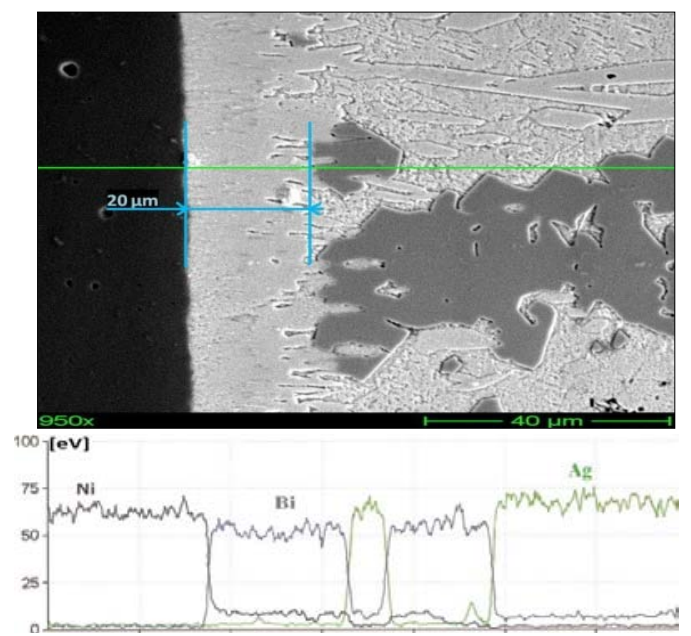

Fig. 4. EDX analysis of BiAg11 solder- Ni substrate fabricated without the use of flux and line profiles of elements present

\section{CONCLUSION}

Better results were recorded with $\mathrm{Cu}$ and $\mathrm{Ag}$ substrates when flux of the Soldaflux type was applied. The results of wetting angles were $25^{\circ}$ for $\mathrm{Cu}$ substrate and $18^{\circ}$ for $\mathrm{Ag}$ substrate which means that both materials are suitable for BiAg11 solder and for its potential application in practice.

In case of Ni substrate it is better not to apply flux. The results of wetting angles are only then satisfactory. In the nearest future, BiAg11 solder has a good perspective to be used in electrical engineering in soldering printed circuit boards directly on a conductive surface (Lee, 2007). It is the first economically advantageous lead-free solder which can be used to solder printed circuit boards and which is able to withstand the temperature of $260{ }^{\circ} \mathrm{C}$ during the reflow soldering (Rahn, 2006).

\section{ACKNOWLEDGEMENTS}

This contribution was prepared with the support of the project VEGA 1/0211/11 Development of lead - free solder for higher application temperatures and research of material solderability of metallic and ceramic material.

\section{REFERENCES}

Zhao, J.; Qi, L.; Wang, X. \& Wang, L. (2004). Influence of Bi on microstructures Evolution and mechanical properties in $\mathrm{Sn}-\mathrm{Ag}-\mathrm{Cu}$ lead free solder. Journal of Alloys and Compounds, Vol. 8., No. 12, (19-21), ISSN 1213-9829

Liang, A. J. (2007). Mettalurgic processing and Reliability of lead-free Solder Joint Interconnectrons. Hophinton: EMC Corp., 2007. ISBN 0-387-27974-1

Song, J. M.; Chuang, H. Y. \& Wui, Z. M. (2006). Interfacial Reactions between Bi-Ag Solders. Journal of Electronic materials, Vol. 9, No. 5, (9-11), ISSN 1346-9761

Rahn, A. (2006). The Basic of Soldering, Jason Wiley \& sons, Inc., (62-64), ISBN 0-471-58471-1

Lee, N. J. (2007). Reflow Soldering Procesess and Troubleshooting, Newnes, (98-101), ISBN 0-7506-7218-8 